\title{
Enhancement of Stretch Formability at Room Temperature by Addition of Ca in Mg-Zn Alloy
}

\author{
Yasumasa Chino $^{1, *}$, Xinsheng Huang ${ }^{1}$, Kazutaka Suzuki ${ }^{1}$ and Mamoru Mabuchi ${ }^{2}$ \\ ${ }^{1}$ Materials Research Institute for Sustainable Development, National Institute of Advanced Industrial Science and Technology, \\ Nagoya 463-8560, Japan \\ ${ }^{2}$ Department of Energy Science and Technology, Graduate School of Energy Science, Kyoto University, Kyoto 606-8501, Japan
}

\begin{abstract}
The stretch formability of a rolled $\mathrm{Mg}-1.5 \mathrm{Zn}-0.1 \mathrm{Ca}$ alloy sheet was investigated at room temperature. The Mg alloy showed a large Erichsen value of 8.2. This is due to a reduction in intensity of basal plane texture and a spreading of the basal poles towards the transverse direction. It is suggested that solid solution of $\mathrm{Ca}$ atoms into $\mathrm{Mg}$ plays a critical role in the unique texture formation. Activation of non-basal slips by dilute $\mathrm{Ca}$ addition was hypothesized to be related to the unique texture formation. [doi:10.2320/matertrans.M2009385]
\end{abstract}

(Received November 18, 2009; Accepted January 18, 2010; Published March 3, 2010)

Keywords: magnesium alloys, rolling, texture, stretch formability

Magnesium alloys are promising structural light materials because of their high specific strength, high specific stiffness and so on. The use of Mg alloys is expanding, particularly in automobile industry and consumer electronics industry. For their greater applicability, high formability $\mathrm{Mg}$ alloy sheets should be developed. However, (0002) basal planes are aligned parallel to the rolling direction (RD) and the intense basal plane texture is formed during rolling, results in poor formability at room temperature in rolled $\mathrm{Mg}$ alloy sheets.

Recently, Mg alloy sheets showing high stretch formability at room temperature have been developed through two means. One is improved rolling technologies such as differential speed rolling, ${ }^{1-3)}$ cross rolling ${ }^{4)}$ and high temperature rolling. ${ }^{2,3,5,6)}$ The intensity of basal plane texture is reduced by the improved rolling methods, and therefore, the stretch formability of the rolled $\mathrm{Mg}$ sheets is enhanced. Huang et al. $^{2)}$ showed that a large Erichsen value of 9.5 is obtained in AZ31 Mg alloy produced by differential speed rolling at high temperature of $823 \mathrm{~K}$. Addition of special elements such as $\mathrm{Ce}, \mathrm{Y}, \mathrm{Gd}$ and $\mathrm{La}$ is another route for enhancement of stretch formability at room temperature in Mg alloys. ${ }^{7-9)}$ For example, it has been reported that a rolled Mg-1.5 mass\% $\mathrm{Zn}$ 0.2 mass \%Ce alloy sheet shows a large Erichsen value of 9.0 at room temperature. ${ }^{7)}$ Addition of the special elements gives rise not only to a reduction in intensity of basal plane texture, but also to a spreading of the basal poles towards the RD or the transverse direction (TD). ${ }^{8-14)}$ Such unique texture by the addition of special elements is obtained during extruding as well. ${ }^{15-18)}$ However, these additional elements are rare and high cost materials. This is a big problem for commercial applications.

The present paper describes enhancement of stretch formability at room temperature by very low $\mathrm{Ca}$ addition of 0.066 mass\% to $\mathrm{Mg}-1.52$ mass\% $\mathrm{Zn}$ alloy. The rolled $\mathrm{Mg}-\mathrm{Zn}$ Ca alloy exhibited a large Erichsen value of 8.2 at room temperature, while a rolled $\mathrm{Mg}-\mathrm{Zn}$ alloy showed a low Erichsen value of 3.4 at room temperature. This finding of the enhanced stretch formability by the $\mathrm{Ca}$ addition is very

*Corresponding author, E-mail: y-chino@aist.go.jp interesting in terms of both commercial and scientific aspects.

An extruded Mg-1.52 mass\%Zn-0.066 mass\%Ca alloy (Mg-1.5Zn-0.1Ca alloy) with $50 \mathrm{~mm}$ in length, $60 \mathrm{~mm}$ in width and $5 \mathrm{~mm}$ in thickness was prepared as an as-received specimen. The specimen was heated at $663 \mathrm{~K}$ or $1.2 \times 10^{3} \mathrm{~s}$ in a furnace, and a unidirectional rolling was conducted at a rolling reduction of $20 \%$, where the temperature of roll surface was held at $353 \mathrm{~K}$. The heating and rolling treatments were repeated, and the sheet was rolled to a thickness of $1 \mathrm{~mm}$. The rolling direction was perpendicular to the extrusion direction. Finally, the rolled specimen was annealed at $623 \mathrm{~K}$ for $5.4 \times 10^{3} \mathrm{~s}$. As a reference, the rolled $\mathrm{Mg}-1.50$ mass $\% \mathrm{Zn}$ alloy (Mg-1.5Zn alloy) was processed by the same manner with the rolled $\mathrm{Mg}-\mathrm{Zn}-\mathrm{Ca}$ alloy. The chemical compositions of $\mathrm{Mg}-\mathrm{Zn}$ and $\mathrm{Mg}-\mathrm{Zn}-\mathrm{Ca}$ alloys are listed in Table 1.

Figure 1 shows microstructures of the as-extruded $\mathrm{Mg}-\mathrm{Zn}$ and $\mathrm{Mg}-\mathrm{Zn}$-Ca alloys of the ED-ND plane, where the ED and ND are the extrusion and normal directions, respectively. The as-extruded specimens exhibited a duplex microstructure composed of recrystallized fine grains and un-recrystallized coarse grains. It is noted that the recrystallized grains of the $\mathrm{Mg}-\mathrm{Zn}-\mathrm{Ca}$ alloy exhibited finer grain size compared with those of the $\mathrm{Mg}-\mathrm{Zn}$ alloy. The (0002) pole figures of the extrusions are shown in Fig. 2. The ring fiber texture with the $(0002)$ basal planes parallel to the extrusion direction was observed in both the alloys. The Mg-Zn-Ca alloy showed weaker texture intensity compared with the $\mathrm{Mg}-\mathrm{Zn}$ alloy.

Microstructures of the rolled and subsequently annealed $\mathrm{Mg}-\mathrm{Zn}$ and $\mathrm{Mg}-\mathrm{Zn}-\mathrm{Ca}$ alloys were shown in Fig. 3. The grain

Table 1 Chemical compositions (mass\%) of the $\mathrm{Mg}-1.5 \mathrm{Zn}$ and $\mathrm{Mg}-1.5 \mathrm{Zn}$ $0.1 \mathrm{Ca}$ alloys.

\begin{tabular}{cccccc}
\hline Specimen & $\mathrm{Zn}$ & $\mathrm{Ca}$ & $\mathrm{Cu}$ & $\mathrm{Ni}$ & $\mathrm{Fe}$ \\
\hline $\mathrm{Mg}-1.5 \mathrm{Zn}$ & 1.50 & 0.0003 & 0.0038 & $<0.0005$ & 0.0050 \\
\hline $\mathrm{Mg}-1.5 \mathrm{Zn}-0.1 \mathrm{Ca}$ & 1.52 & 0.0660 & 0.0032 & $<0.0005$ & 0.0047 \\
\hline
\end{tabular}



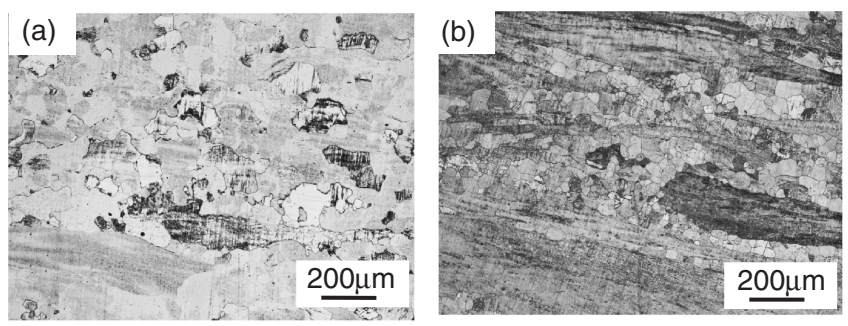

Fig. 1 Optical micrographs of the as-extruded $\mathrm{Mg}$ alloys, where the EDND plane is observed: (a) Mg-1.5Zn alloy and (b) Mg-1.5Zn-0.1Ca alloy.

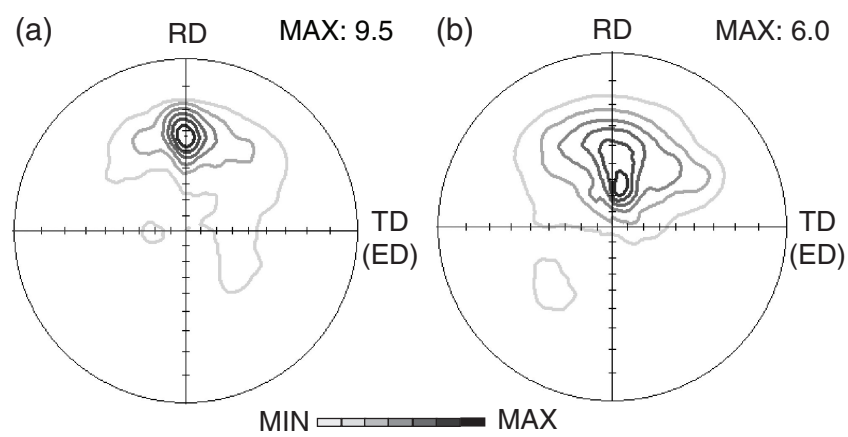

Fig. 2 (0002) pole figures of the as-extruded $\mathrm{Mg}-1.5 \mathrm{Zn}$ alloy (a) and $\mathrm{Mg}$ $1.5 \mathrm{Zn}-0.1 \mathrm{Ca}$ alloy (b)

(a)
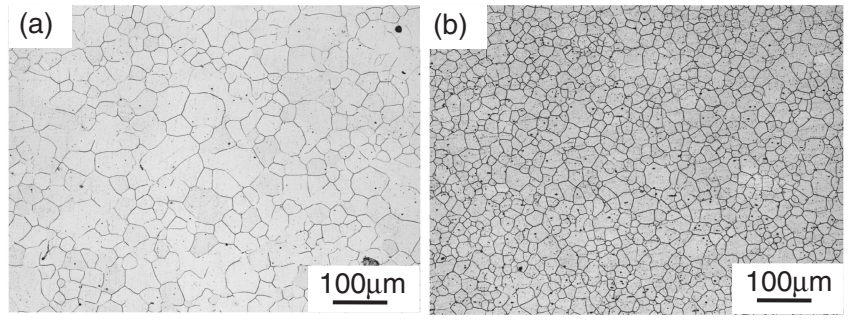

Fig. 3 Optical micrographs of the $\mathrm{Mg}-1.5 \mathrm{Zn}$ alloy (a) and $\mathrm{Mg}-1.5 \mathrm{Zn}-0.1 \mathrm{Ca}$ alloy rolled at $723 \mathrm{~K}$ and subsequently annealed at $623 \mathrm{~K}$, where the RDND plane is observed.

size of the rolled and subsequently annealed $\mathrm{Mg}-\mathrm{Zn}$ and $\mathrm{Mg}$ $\mathrm{Zn}-\mathrm{Ca}$ alloy was $63 \mu \mathrm{m}$ and $32 \mu \mathrm{m}$, respectively, indicating that addition of $\mathrm{Ca}$ in $\mathrm{Mg}-\mathrm{Zn}$ promoted grain refinement. Previous studies revealed that dilute addition of $0.1-1.0$ mass\% Ca to pure $\mathrm{Mg}^{19)}$ and $\mathrm{Mg}-\mathrm{Zn}$ alloy ${ }^{20)}$ was effective for grain refinement of the as-cast $\mathrm{Mg}$ alloys. It is accepted that grain refinement by dilute $\mathrm{Ca}$ addition is attained by restriction of grain growth and promotion of nucleation of primary $\mathrm{Mg}$ during solidification. ${ }^{19,20)}$ Figures 1 and 3 suggest that dilute $\mathrm{Ca}$ addition to $\mathrm{Mg}-\mathrm{Zn}$ alloy contributes to not only grain refinement during solidification but also grain refinement due to recrystallization during extrusion, rolling and annealing.

The (0002) pole figures of the rolled $\mathrm{Mg}$ alloys prior annealing at $623 \mathrm{~K}$ are shown in Fig. 4(a) and (b). The intensity of basal plane texture was reduced by the $\mathrm{Ca}$ addition in the same manner as the as-extruded $\mathrm{Mg}-\mathrm{Zn}-\mathrm{Ca}$ alloy. Besides, the basal poles were split toward the RD in the $\mathrm{Mg}-\mathrm{Zn}-\mathrm{Ca}$ alloy, on the other hand, the basal pole was slightly tilted toward the RD in the Mg-Zn alloy. The (0002)

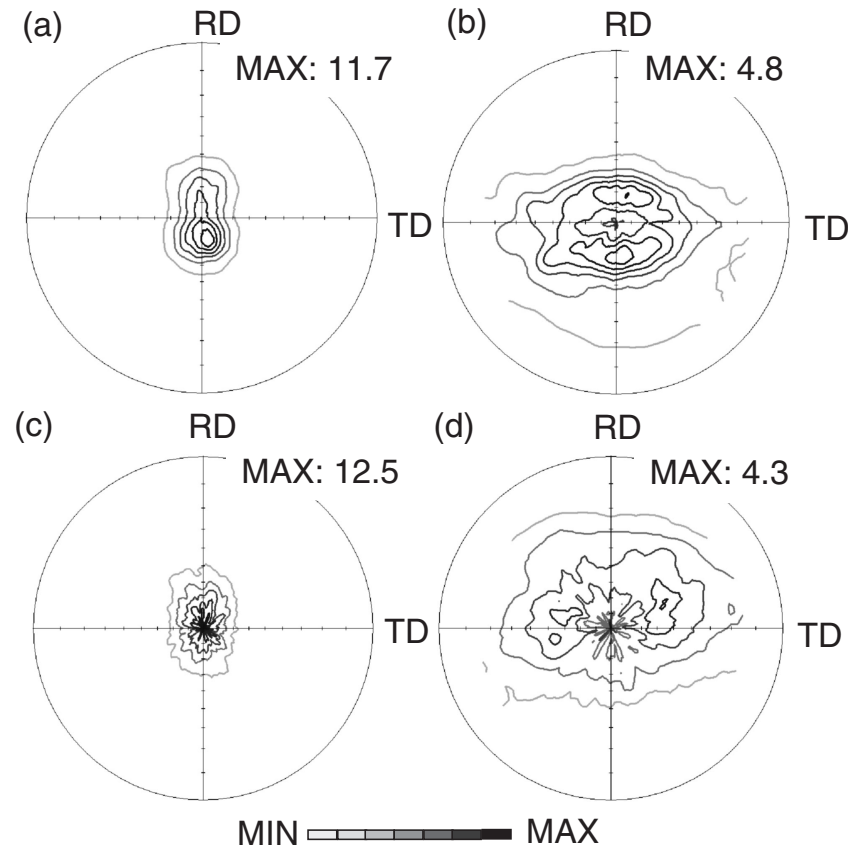

Fig. 4 (0002) pole figures of the rolled Mg-1.5Zn alloy (a) and rolled Mg$1.5 \mathrm{Zn}-0.1 \mathrm{Ca}$ alloy (b), rolled and subsequently annealed $\mathrm{Mg}-1.5 \mathrm{Zn}$ alloy (c) and rolled and subsequently annealed $\mathrm{Mg}-1.5 \mathrm{Zn}-0.1 \mathrm{Ca}$ alloy (d).

pole figures of the rolled and subsequently annealed $\mathrm{Mg}$ alloys are shown in Fig. 4(c) and (d). It is of interest to note that the basal poles were tilted toward the TD in the annealed $\mathrm{Mg}-\mathrm{Zn}-\mathrm{Ca}$ alloy, although they were tilted toward the RD prior annealing. This unique texture is the same as that in the rolled and annealed $\mathrm{Mg}-\mathrm{Zn}-\mathrm{Ce}$ alloy. ${ }^{14)} \mathrm{A}$ change in tilt of basal poles from the RD to the TD by annealing points out the importance of static recrystallization during annealing. On the other hand, the basal planes tended to be aligned parallel to the RD more intensely by annealing in the $\mathrm{Mg}-\mathrm{Zn}$ alloy. Deformation heterogeneities such as shear bands occurred during hot rolling not only in the $\mathrm{Mg}-\mathrm{Zn}-\mathrm{Ca}$ alloy, but also in the $\mathrm{Mg}-\mathrm{Zn}$ alloy. This indicates that the unique texture formation in the $\mathrm{Mg}-\mathrm{Zn}-\mathrm{Ca}$ alloy is not due to occurrence of deformation heterogeneities such as shear bands. ${ }^{12,18)}$

The normal stress-strain curves by tensile tests at room temperature are shown in Fig. 5, where tensile tests are carried out at the angle between the tensile direction and the rolling direction of 0,45 and 90 degrees. The stress-strain relation at the angle of 0 degree for the $\mathrm{Mg}-\mathrm{Zn}-\mathrm{Ca}$ alloy was almost the same as that for the $\mathrm{Mg}-\mathrm{Zn}$ alloy. On the other hand, at the angles of 45 and 90 degrees, the strength was lower, but the ductility was larger in the $\mathrm{Mg}-\mathrm{Zn}-\mathrm{Ca}$ alloy than in the $\mathrm{Mg}-\mathrm{Zn}$ alloy. The grain size of the $\mathrm{Mg}-\mathrm{Zn}-\mathrm{Ca}$ alloy was smaller than that of the $\mathrm{Mg}-\mathrm{Zn}$ alloy. Therefore, the lower strength for the $\mathrm{Mg}-\mathrm{Zn}-\mathrm{Ca}$ alloy is due to the texture softening. ${ }^{16)}$

The tensile properties at room temperature are summarized in Table 2. The strain-hardening exponent (the $n$-value) for the $\mathrm{Mg}-\mathrm{Zn}-\mathrm{Ca}$ alloy was larger than or nearly equal to that for the Mg-Zn alloy. Also, the Lankford value (the $r$-value) for the former was lower than that for the latter. The unique texture for the $\mathrm{Mg}-\mathrm{Zn}-\mathrm{Ca}$ alloy is responsible for the large $n$ value $^{9)}$ and the low $r$-value. ${ }^{11)}$ 


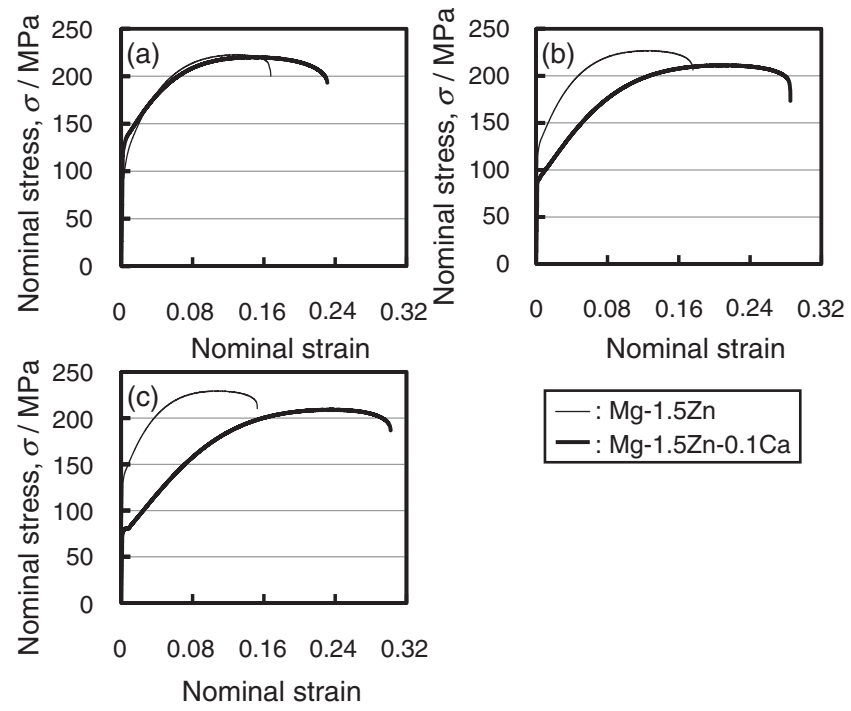

Fig. 5 Nominal stress-strain curves for the $\mathrm{Mg}-1.5 \mathrm{Zn}$ and $\mathrm{Mg}-1.5 \mathrm{Zn}$ $0.1 \mathrm{Ca}$ alloys at different angles between the tensile direction and the rolling direction: (a) $0 \mathrm{deg}$, (b) $45 \mathrm{deg}$ and (c) $90 \mathrm{deg}$.

Table 2 Tensile properties at room temperature of the $\mathrm{Mg}-1.5 \mathrm{Zn}$ and $\mathrm{Mg}$ $1.5 \mathrm{Zn}-0.1 \mathrm{Ca}$ alloys rolled at $723 \mathrm{~K}$ and subsequently annealed at $623 \mathrm{~K}$ (UTS, ultimate tensile stress; TYS, tensile $0.2 \%$ yield stress; FE, elongation to failure; $n, n$-value; $r, r$-value; $r_{\text {ave }}$, average $r$-value).

\begin{tabular}{llcccccc}
\hline \multicolumn{1}{c}{ Alloys } & Angle & $\begin{array}{c}\text { UTS } \\
(\mathrm{MPa})\end{array}$ & $\begin{array}{c}\text { TYS } \\
(\mathrm{MPa})\end{array}$ & $\begin{array}{c}\text { FE } \\
(\%)\end{array}$ & $n$ & $r$ & $r_{\text {ave }}$ \\
\hline \multirow{3}{*}{ Mg-1.5Zn } & 0 & 222 & 84 & 17 & 0.32 & 1.45 & \\
& 45 & 227 & 117 & 18 & 0.29 & 1.65 & 1.65 \\
& 90 & 229 & 131 & 15 & 0.25 & 1.86 & \\
Mg-1.5Zn-0.1Ca & 0 & 220 & 120 & 23 & 0.30 & 0.84 & \\
& 45 & 211 & 86 & 29 & 0.44 & 0.80 & 0.81 \\
& 90 & 209 & 73 & 30 & 0.50 & 0.79 & \\
\hline
\end{tabular}

The results of the Erichsen tests at room temperature are shown in Fig. 6. The Mg-Zn-Ca showed a large Erichsen value of 8.2 at room temperature. This value is almost the same as those of commercial $\mathrm{Al}$ alloys. ${ }^{7)}$ It is noted that the high stretch formability is attained by very low $\mathrm{Ca}$ addition of 0.066 mass $\%$ or 0.024 at $\%$, not by the addition of rare earth metals such as Ce.

It is known that the large strain-hardening exponent leads to a reduction in plastic instability, resulting in enhanced stretch formability. In some works, ${ }^{9,21)}$ the importance of large strain-hardening exponent was pointed out for the enhanced stretch formability of $\mathrm{Mg}$ alloys. In the present work as well, the large strain-hardening exponent was obtained in the $\mathrm{Mg}-\mathrm{Zn}-\mathrm{Ca}$, as shown in Table 2. However, because straining in the thickness direction is essentially required under the biaxial tensile stress state, the stretch formability of $\mathrm{Mg}$ with strong plastic anisotropy is mainly dominated by the control of texture. ${ }^{21)}$ The grain size is also one of microstructural factors affecting the stretch formability because ductility is increased by decreasing grain size in Mg. ${ }^{22)}$ However, it was recently reported that the stretch formability at room temperature is enhanced by coarsening of the grain size. ${ }^{23)}$ Therefore, the enhanced stretch formability for the $\mathrm{Mg}-\mathrm{Zn}-\mathrm{Ca}$ alloy is not due to the larger $n$-value and (a)

$\mathrm{IE}=3.4$

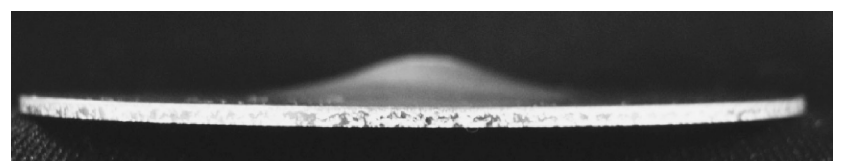

(b)

$\mathrm{IE}=8.2$

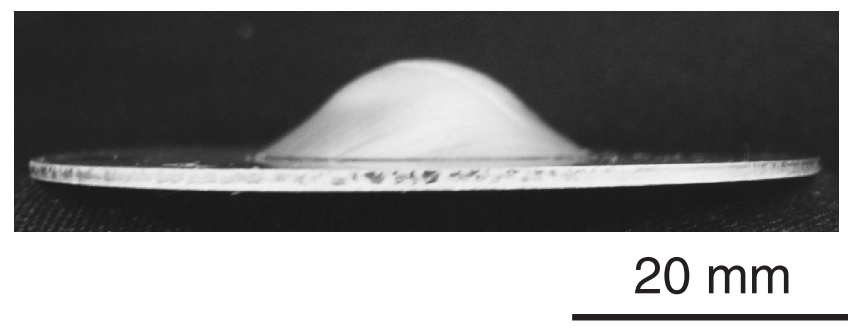

Fig. 6 Specimens after the Erichsen tests at room temperature, (a) Mg$1.5 \mathrm{Zn}$ alloy and (b) $\mathrm{Mg}-1.5 \mathrm{Zn}-0.1 \mathrm{Ca}$ alloy.

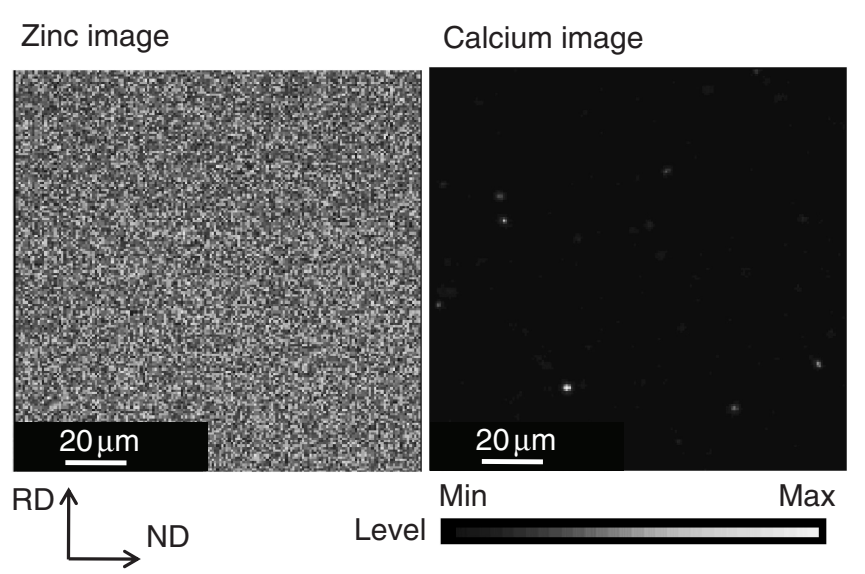

Fig. 7 Zinc and calcium images by EPMA for the Mg-1.5Zn-0.1Ca alloy, where the RD-ND plane is observed.

the smaller grain size, but to the unique texture, that is, a reduction in intensity of basal plane texture and a spreading of the basal poles towards the TD.

Recrystallization behavior strongly affects the texture formation. It was suggested that particle-stimulated nucleation (PSN) plays an important role for the unique texture formation in $\mathrm{Mg}$ alloys containing rare earth metals. ${ }^{15,16)}$ For PSN, large particles of diameter greater than about $1 \mu \mathrm{m}$ are required. ${ }^{24)}$ However, such large particles were not observed in the Mg-Zn-Ca alloy, as shown in Fig. 7. Therefore, it is unlikely that PSN is the major contribution to the formation of unique non-basal texture. ${ }^{17,18,25,26)}$

Spreading of basal poles to the TD is typical of the texture of deformed $\mathrm{Zr}$ alloys, ${ }^{27)}$ in which non-basal $\langle c\rangle$ and $\langle c+a\rangle$ slips occurs more readily than basal $\langle a\rangle$ slips. Therefore, it is hypothesized that activation of non-basal slips such as $\langle c+a\rangle$ slips are related to the formation of unique non-basal texture in the Mg-Zn-Ca alloy. The Peierls stress for nonbasal slips is decreased with decreasing $c / a$ lattice constant ratio. It was reported that the $c / a$ ratio was decreased from $1.6244\left(=c / a\right.$ ratio of pure $\left.\mathrm{Mg}^{28}\right)$ to $1.6237-1.6213$ by the $\mathrm{Y}$ addition in $\mathrm{Mg}-\mathrm{Zn}-\mathrm{Y}$ alloys. ${ }^{8}$ ) On the other hand, no decrease in $c / a$ ratio was obtained in the $\mathrm{Mg}$-Ce alloy due to the small 
Table 3 Lattice parameters of the rolled $\mathrm{Mg}-1.5 \mathrm{Zn}$ and $\mathrm{Mg}-1.5 \mathrm{Zn}-0.1 \mathrm{Ca}$ alloys.

\begin{tabular}{llll}
\hline \multicolumn{1}{c}{ Alloys } & $a(\mathrm{~nm})$ & $c(\mathrm{~nm})$ & $c / a$ \\
\hline $\mathrm{Mg}-1.5 \mathrm{Zn}$ & 3.2072 & 5.2073 & 1.6236 \\
$\mathrm{Mg}-1.5 \mathrm{Zn}-0.1 \mathrm{Ca}$ & 3.2080 & 5.2065 & 1.6230 \\
\hline
\end{tabular}

addition of 0.035 at $\%{ }^{28)}$ The lattice constants are listed in Table 3 for the $\mathrm{Mg}-\mathrm{Zn}$ and the $\mathrm{Mg}-\mathrm{Zn}$-Ca alloys. A decrease in $c / a$ ratio by the Ca addition is not as large as those by the $\mathrm{Y}$ addition, and therefore, the active non-basal slips cannot be explained only by a decrease in $c / a$ ratio due to the $\mathrm{Ca}$ addition.

An increase in stacking fault energy by the $\mathrm{Ca}$ addition is another possibility for the active non-basal slips. ${ }^{29)}$ However, the first principle calculation showed that the stacking fault energy is decreased by the $\mathrm{Ca}$ addition. ${ }^{30}$ ) Therefore, a change in stacking fault energy by the $\mathrm{Ca}$ addition is not responsible for the active non-basal slips. Further work is underway to understand the relationships between the $\mathrm{Ca}$ addition in $\mathrm{Mg}-\mathrm{Zn}$ alloy and the activity of non-basal slips.

Stanford et al. ${ }^{18)}$ investigated effects of $\mathrm{Al}, \mathrm{Sn}, \mathrm{Ca}, \mathrm{La}$ and $\mathrm{Gd}$ additions and they showed no reduction in intensity of basal plane texture and no formation of non-basal texture in the Ca-containing $\mathrm{Mg}$ alloy. In their work, many particles were precipitated in the Ca-containing $\mathrm{Mg}$ alloy. In the present work, however, the $\mathrm{Mg}-\mathrm{Zn}-\mathrm{Ca}$ alloy is a solid solution alloy containing few small precipitates, as shown in Fig. 7. Therefore, it is suggested that solid solution of $\mathrm{Ca}$ atoms into $\mathrm{Mg}$ plays a critical role in formation of the nonbasal texture. Even a very low $\mathrm{Ce}$ addition of 0.035 at\% activates the non-basal slip of $\mathrm{Mg} .{ }^{28)}$ In the present work, the $\mathrm{Ca}$ addition is 0.024 at\%. Noted that such low additions drastically affect the deformation behavior of $\mathrm{Mg}$.

In conclusion, the $\mathrm{Mg}-1.52$ mass $\% \mathrm{Zn}-0.066$ mass $\% \mathrm{Ca}$ alloy, rolled at $723 \mathrm{~K}$ and subsequently annealed at $623 \mathrm{~K}$, showed a large Erichsen value of 8.2 at room temperature. This is comparable to those of commercial Al alloys. The $\mathrm{Mg}-\mathrm{Zn}-\mathrm{Ca}$ alloy showed the unique texture, that is, a reduction in intensity of basal plane texture and a spreading of the basal poles towards the TD. It is suggested that solid solution of $\mathrm{Ca}$ atoms into $\mathrm{Mg}$ plays a critical role in the unique texture formation. Activation of non-basal slips by dilute $\mathrm{Ca}$ addition is hypothesized to be related to the unique texture formation.

\section{REFERENCES}

1) Y. Chino, M. Mabuchi, R. Kishihara, H. Hosokawa, Y. Yamada, C. E. Wen, K. Shimojima and H. Iwasaki: Mater. Trans. 43 (2002) 25542560.

2) X. Huang, K. Suzuki and N. Saito: Scr. Mater. 61 (2009) 445-448.

3) X. Huang, K. Suzuki and N. Saito: Scr. Mater. 60 (2009) 651-654.

4) Y. Chino, K. Sassa and M. Mabuchi: J. Mater. Sci. 44 (2009) 18211827.

5) Y. Chino and M. Mabuchi: Scr. Mater. 60 (2009) 447-450.

6) Y. Chino, K. Sassa and M. Mabuchi: J. Mater. Sci. 44 (2009) 45934598.

7) Y. Chino, K. Sassa and M. Mabuchi: Mater. Trans. 49 (2008) 17101712.

8) Y. Chino, K. Sassa and M. Mabuchi: Mater. Sci. Eng. A 513-514 (2009) 394-400.

9) D. H. Kang, D. W. Kim, S. Kim, G. T. Bae, K. H. Kim and N. J. Kim: Scr. Mater. 61 (2009) 768-771.

10) S. R. Agnew, M. H. Yoo and C. N. Tome: Acta Mater. 49 (2001) 42774289.

11) J. Bohlen, M. R. Nurnberg, J. W. Senn, D. Letzig and S. R. Agnew: Acta Mater. 55 (2007) 2101-2112.

12) L. W. F. Mackenzie and M. O. Pekguleryuz: Scr. Mater. 59 (2008) 665668.

13) K. Hantzsche, J. Wendt, K. U. Kainer, J. Bohlen and D. Letzig: JOM 69 (2009) 38-42.

14) Y. Chino, K. Sassa and M. Mabuchi: Mater. Trans. 49 (2008) 29162918.

15) E. A. Ball and P. B. Prangnell: Scr. Metall. Mater. 31 (1994) 111-116.

16) R. K. Mishra, A. K. Gupta, P. R. Rao, A. K. Sachdev, A. M. Kumar and A. A. Luo: Scr. Mater. 59 (2008) 562-565.

17) N. Stanford and M. Barnett: Scr. Mater. 58 (2008) 179-182.

18) N. Stanford and M. Barnett: Mater. Sci. Eng. A 496 (2008) 399-408.

19) Y. C. Lee, A. K. Dahle and D. H. StJohn: Metall. Mater. Trans. A 31 (2000) 2895-2906.

20) E. Zhang and L. Yang: Mater. Sci. Eng. A 497 (2008) 111-118.

21) Y. Chino, H. Iwasaki and M. Mabuchi: Mater. Sci. Eng. A 466 (2007) 90-95.

22) J. A. Chapman and D. V. Wilson: J. Inst. Metals 92 (1962) 39-40.

23) Y. Chino, K. Kimura and M. Mabuchi: Acta Mater. 57 (2009) 14761485 .

24) F. J. Humphreys: Mater. Sci. Eng. A 135 (1991) 267-273.

25) L. W. F. Mackenzie, B. Davis, F. J. Humphreys and G. W. Lorimer: Mater. Sci. Tech. 23 (2007) 1173-1180.

26) R. Cottam, J. Robson, G. Lorimer and B. Davis: Mater. Sci. Eng. A 485 (2008) 375-382.

27) E. Tenckhoff: Deformation mechanisms, texture, and anisotropy in zirconium and zircaloy, first ed., (ASTM special technical publication, Philadelphia, 1988).

28) Y. Chino, M. Kado and M. Mabuchi: Acta Mater. 56 (2008) 387-394.

29) Y. Chino, M. Kado and M. Mabuchi: Mater. Sci. Eng. A 494 (2008) 343-349.

30) T. Uesugi and K. Higashi: J. JILM 54 (2004) 82-89. 